\title{
sciendo
}

\section{Evaluation of Perceptions of Smile Esthetics by Dental Students}

\section{SUMMARY}

Background/Aim: The aim of this study was to investigate in the esthetic perceptions of 2nd grade dental students before and after training. Material and Methods: A total of 16 photographs which contain golden ratio, buccal corridor, midline deviation, incisal embrasure, lip line, midline diastema, dark triangles and smile arc were shown to 78 dental students (33 male, 45 female). Immediately after the training about the smile esthetics, the same photos were shown again. The effect of gender on esthetic perception was also examined, in addition to assessing the effects of education on esthetic perception. Pearson Chi-square, Fisher's Exact test and McNemar test were used in the analysis of the results. Results: According to the results of the analysis, it was found that the answers of the smile arc before and after the education were statistically significant $(p<0.05)$. Accordingly, the rate of correct answers of women is statistically higher than that of men. A statistically significant difference was found between the responses to the gingival appearance in the smile before and after the education ( $p<0.05)$. Conclusions: Based on the limited results of this study, professional dental education may affect the esthetic evaluation of smile. There were differences in the esthetic perception of women and men.

Key words: Dental Students, Esthetics, Perception, Prosthodontics, Smile Arc.

\section{Gamze Paken, Merve Ünal}

Department of Prosthodontics, College of Dentistry, Usak University, Usak, Turkey

ORIGINAL PAPER (OP)

Balk J Dent Med, 2021;100-107

\section{Introduction}

Esthetics, which is often used interchangeably with beauty, is a combination of qualities that influences an observer's perception. The attractiveness of a smile can have an effect on social relationships ${ }^{1,2}$. Esthetic dentistry plays a significant role in the professional practice of dentists as well as in the lives of patients. This is particularly relevant these days because the media encourages attractiveness in pretty faces and flawless smiles, which are both connected to good health and physical and mental well-being ${ }^{3,4}$. Since beauty is a highly debatable concept, the esthetic appearance of a patient's smile largely depends on what a clinician characterizes as attractive ${ }^{5}$.

Esthetic smile design is a dynamic process that involves a multidisciplinary approach ${ }^{6,7}$. Clinicians should evaluate the variables of smile design, such as 
dental, gingival, and facial esthetics ${ }^{8}$ because esthetics depends on harmony among these parameters. In an effort to understand the roles of the various circumstances of esthetics in the perception of attractiveness, guidelines for the reconstruction of facial and dental esthetics were developed ${ }^{9}$. The establishment of esthetic parameters may significantly reduce unnecessary treatment and misunderstanding with patients ${ }^{5}$. Therefore, dentists should consider the patient's hopes and expectations during the first visit ${ }^{7}$.

In recent years, research has concentrated on quantifying facial and dental esthetics to improve the quality of prosthodontic, orthodontic, and periodontal treatment. For this reason, clinicians have started to incorporate esthetic parameters into their practices ${ }^{10}$. Esthetic parameters, such as buccal corridor, smile line, smile arc, midline shift, angulation of teeth, midline diastema, golden ratio, incisal embrasure, dark triangles, vertical lip thickness, maxillary central incisor symmetry and ratio, tooth angulation, connector space, and contact areas, make up the guidelines that have been developed through various research ${ }^{8,11-15}$.

Vertical anterior dental disorder is one of the most important aspects of facial and dental esthetics. Therefore, gingival and dental disorders and asymmetries need to be carefully analyzed ${ }^{6}$. A balanced and symmetrical composition of teeth, incisal contact and embrasures, golden ratio, buccal corridors, visible and healthy gingiva, smile arc, and lips is substantial for an esthetic and satisfying smile according to the concepts of visual perception $^{8,11-13,16}$.

Esthetic perception is a major concern of clinicians ${ }^{14}$. Many studies have compared the perspectives of laypersons with those of orthodontists in order to evaluate the parameters of smile esthetics. They concluded that technical preparation and guidance will improve an individual's esthetic perception. Thus, it is necessary to further examine the outcome of undergraduate and postgraduate dental education about the standards of smile esthetics on the perception of beauty and esthetic judgement by clinicians ${ }^{17}$.

The aim of this study was to determine the esthetic perceptions of second-grade dental students with respect to golden ratio, buccal corridor, midline shift, incisal embrasure, smile line (lip line), midline diastema, dark triangles, and smile arc in order to evaluate their understanding of smile esthetics before and after esthetic dental training.

\section{Material and Methods}

\section{Study population}

This cross-sectional study, which was performed in November 2019 at the Faculty of Dentistry, Usak
University, Turkey, included 78 (33 male and 45 female) second-grade dental students. All of the participants provided verbal consent to take part in this study.

\section{Photo manipulation}

Figures containing smile components with a 600- pixel resolution were designed using with Adobe Photoshop CS3 (Adobe Systems Inc., San José, CA, USA). The modification included eight smile components, namely the golden ratio (Figure 1), buccal corridor (Figure 2), midline shift (Figure 3), incisal embrasure (Figure 4), smile or lip line (Figure 5), midline diastema (Figure 6), dark triangles (Figure 7), and smile arc (Figure $8)$. The images were converted to black and white during presentation to prevent the misleading influence of color on the perception of the observers ${ }^{18}$.

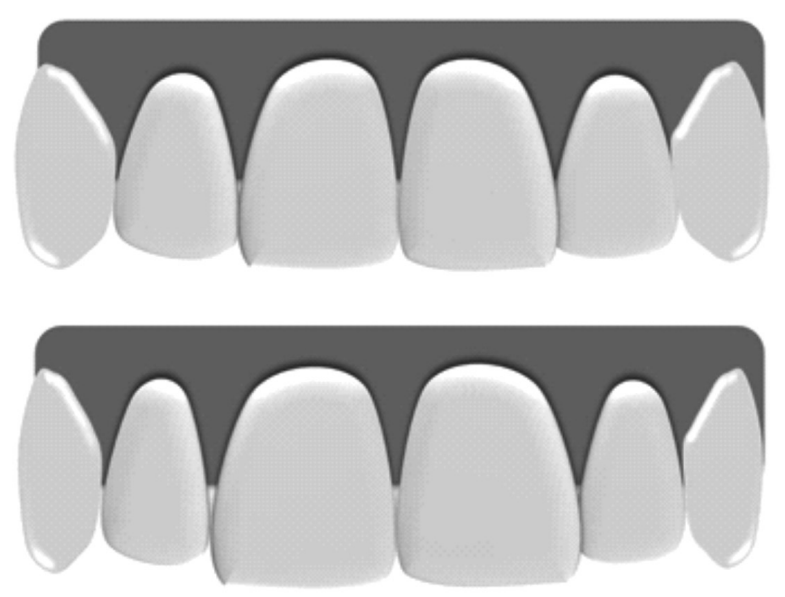

Figure 1. Ideal esthetic appearance (upper) and (lower) altered golden ratio
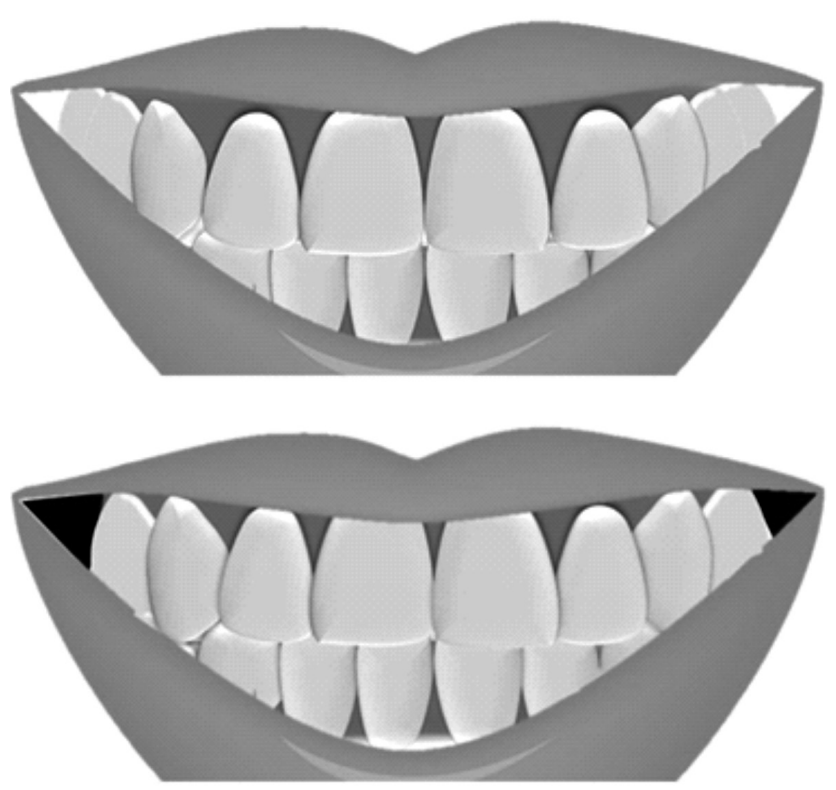

Figure 2. Ideal esthetic appearance (upper) and (lower) altered buccal coridor 

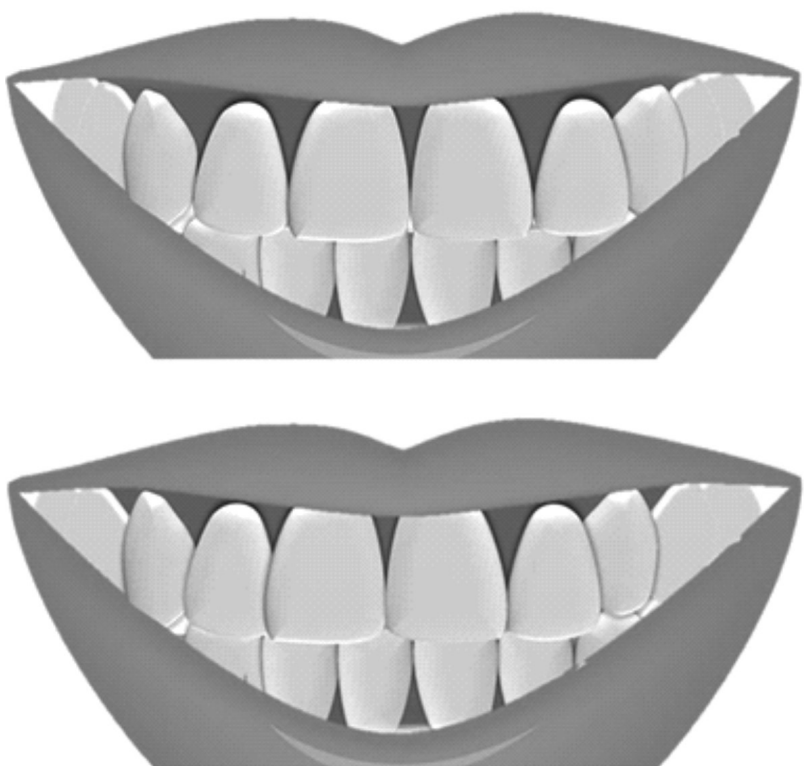

Figure 3. Ideal esthetic appearance (upper) and (lower) altered midline shift
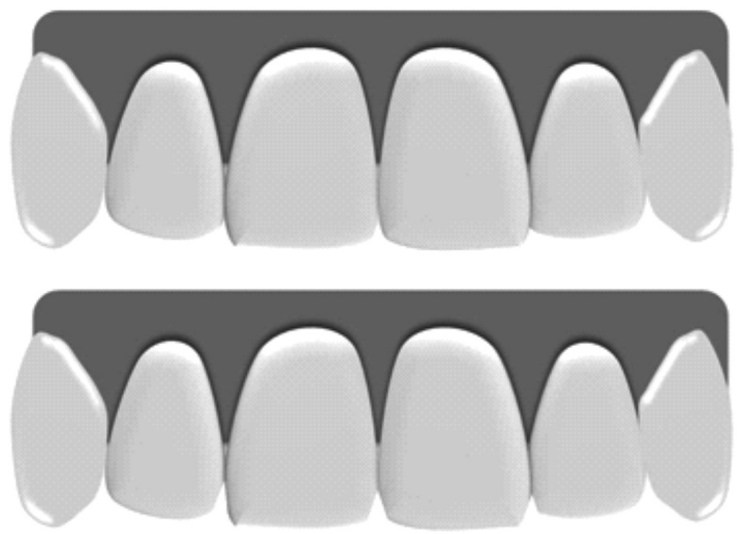

Figure 4. Ideal esthetic appearance (upper) and (lower) altered incisal embrasure
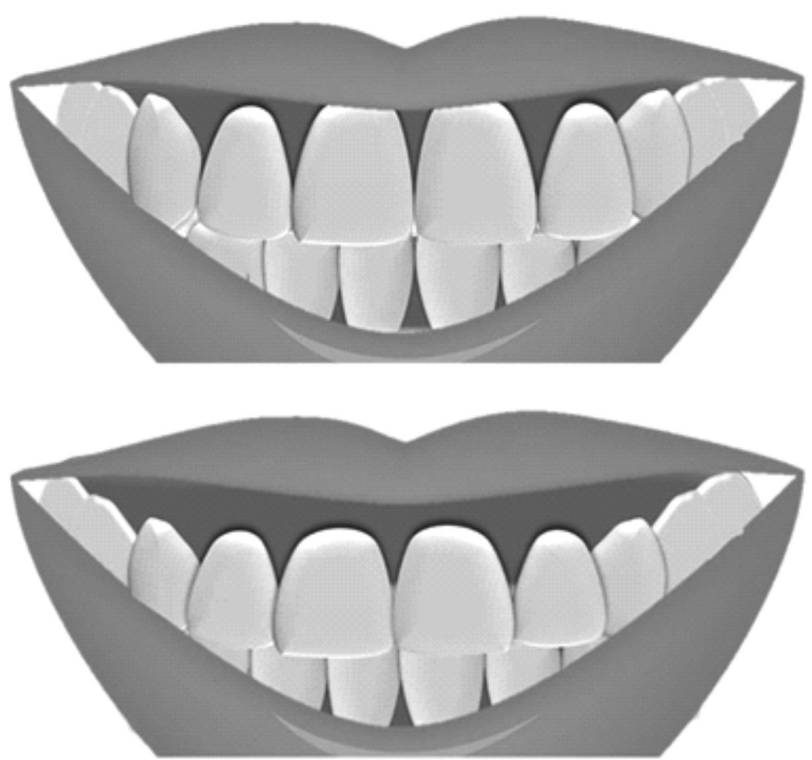

Figure 5. Ideal esthetic appearance (upper) and altered smile or lip line (lower)
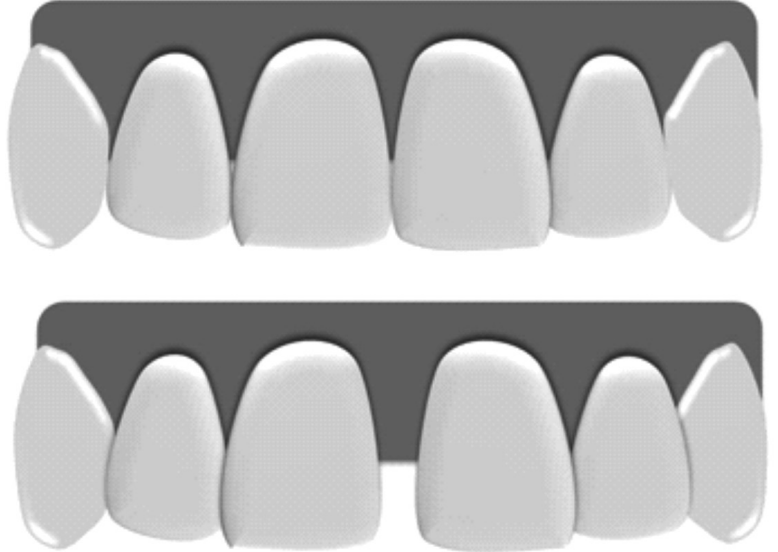

Figure 6. Ideal esthetic appearance (upper) and altered diastema (lower)
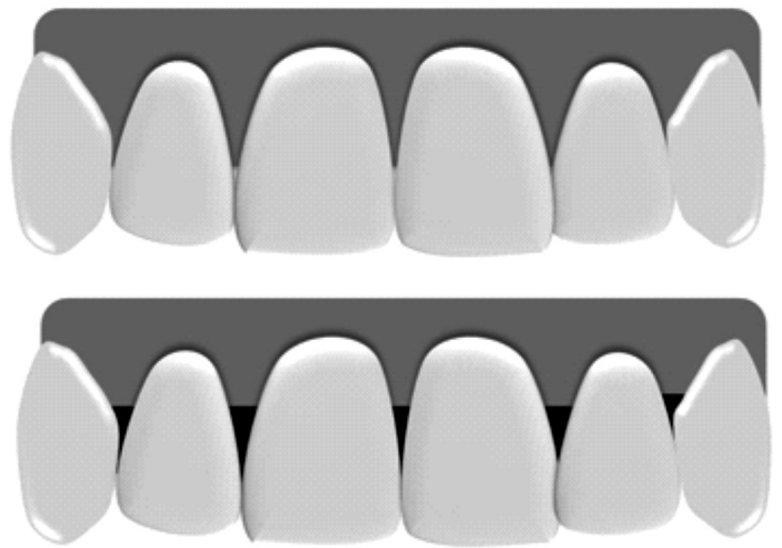

Figure 7. Ideal esthetic appearance (upper) and altered dark triangles (lower)
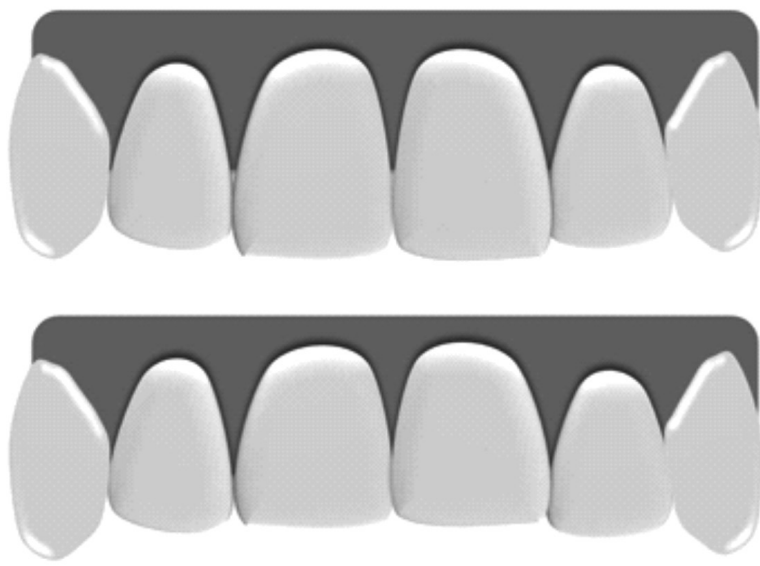

Figure 8. Ideal esthetic appearance (upper) and altered smile arc (lower)

\section{Data collection}

The manipulated images were presented in the form of a PowerPoint presentation to the students in their classroom. A total of 16 photographs containing 
smile esthetic components were shown. After each slide, the students were asked: "Which of the pictures below is the most esthetic from your perspective?" The participants were asked to state their gender and answer the question about the slides on pre-designed answer sheets. Immediately after receiving their education about smile esthetics, the same photos were shown and the same question was asked again.

\section{Statistical analysis}

Data were processed and analyzed using the Statistical Package for the Social Sciences (SPSS) version 25.0 (IBM Corporation, Armonk, NY, USA). Descriptive statistics (frequency and percentage) of the data were obtained for analysis. Pearson's chi-square test was used to examine the relationship between independent categorical data. If the number of samples found in these independent categorical data was insufficient, Fisher's exact test was applied. McNemar inverse sampling was used to examine the differences between the frequencies of dependent categorical data. A $p$ value $<0.05$ was considered statistically significant.

\section{Results}

There were 78 students in the study, including 45 (55.1\%) females and $33(44.9 \%)$ males. No statistically significant differences were found in responses before and after training for golden ratio, buccal corridor, midline shift, incisal embrasure, midline diastema, dark triangles, and smile arc $(p>0.05)$. The only parameter that had a statistically significant difference in responses before and after training was smile or lip line $(\mathrm{p}<0.05)$ (Table 1$)$. There was a statistically significant relationship between gender and the answers given to the smile arc question before and after training $(\mathrm{p}<0.05)$. Female participants were 5.217 times more likely to answer correctly before training (odds ratio $=5.217$ ) and 3.478 times more likely to answer correctly after training compared to the male participants (Table 2, odds ratio=3.478).
Table 1. All parameters are seen as correct and incorrect percentages before and after training

\begin{tabular}{|c|c|c|c|c|c|}
\hline & & & $\mathrm{N}$ & $\%$ & $\mathrm{p}^{*}$ \\
\hline \multirow{4}{*}{$\begin{array}{l}\text { Golden } \\
\text { Ratio }\end{array}$} & \multirow{2}{*}{ Before Training } & Incorrect & 33 & 42.3 & \multirow{4}{*}{0.383} \\
\hline & & Correct & 45 & 57.7 & \\
\hline & \multirow{2}{*}{ After Training } & Incorrect & 28 & 35.9 & \\
\hline & & Correct & 50 & 64.1 & \\
\hline \multirow{4}{*}{$\begin{array}{l}\text { Buccal } \\
\text { Corridor }\end{array}$} & \multirow{2}{*}{ Before Training } & Incorrect & 28 & 35.9 & \multirow{4}{*}{0.585} \\
\hline & & Correct & 50 & 64.1 & \\
\hline & \multirow{2}{*}{ After Training } & Incorrect & 32 & 41.0 & \\
\hline & & Correct & 46 & 59.0 & \\
\hline \multirow{4}{*}{$\begin{array}{l}\text { Midline } \\
\text { Shift }\end{array}$} & \multirow{2}{*}{ Before Training } & Incorrect & 7 & 9.0 & \multirow{4}{*}{1.000} \\
\hline & & Correct & 71 & 91.0 & \\
\hline & \multirow{2}{*}{ After Training } & Incorrect & 7 & 9.0 & \\
\hline & & Correct & 71 & 91.0 & \\
\hline \multirow{4}{*}{$\begin{array}{l}\text { Incisal } \\
\text { Embrasure }\end{array}$} & \multirow{2}{*}{ Before Training } & Incorrect & 30 & 38.5 & \multirow{4}{*}{0.711} \\
\hline & & Correct & 48 & 61.5 & \\
\hline & \multirow{2}{*}{ After Training } & Incorrect & 27 & 34.6 & \\
\hline & & Correct & 51 & 65.4 & \\
\hline \multirow{4}{*}{ Lip Line } & \multirow{2}{*}{ Before Training } & Incorrect & 43 & 55.1 & \multirow{4}{*}{$0.000 *$} \\
\hline & & Correct & 35 & 44.9 & \\
\hline & \multirow{2}{*}{ After Training } & Incorrect & 20 & 25.6 & \\
\hline & & Correct & 58 & 74.4 & \\
\hline \multirow{4}{*}{$\begin{array}{l}\text { Midline } \\
\text { Diastema }\end{array}$} & \multirow{2}{*}{ Before Training } & Incorrect & 3 & 3.8 & \multirow{4}{*}{0.625} \\
\hline & & Correct & 75 & 96.2 & \\
\hline & \multirow{2}{*}{ After Training } & Incorrect & 3 & 3.8 & \\
\hline & & Correct & 75 & 96.2 & \\
\hline \multirow{4}{*}{$\begin{array}{l}\text { Dark Tri- } \\
\text { angle }\end{array}$} & \multirow{2}{*}{ Before Training } & Incorrect & 0 & 0.0 & \multirow{4}{*}{0.625} \\
\hline & & Correct & 78 & 100.0 & \\
\hline & \multirow{2}{*}{ After Training } & Incorrect & 0 & 0.0 & \\
\hline & & Correct & 78 & 100.0 & \\
\hline \multirow{4}{*}{ Smile Arc } & \multirow{2}{*}{ Before Training } & Incorrect & 53 & 67.9 & \\
\hline & & Correct & 25 & 32.1 & \\
\hline & ftor & Incorrect & 51 & 65.4 & $0.02 J$ \\
\hline & Anter 1ranming & Correct & 27 & 34.6 & \\
\hline
\end{tabular}

$(\mathrm{p}<0.05)$ 
Table 2. All parameters are seen as correct and incorrect percentages before and after training according to the gender

\begin{tabular}{|c|c|c|c|c|c|c|}
\hline & & & Incorrect & Correct & Test Value & $\mathrm{p}^{*}$ \\
\hline \multirow{4}{*}{ Golden Ratio } & \multirow[b]{2}{*}{ Before Training } & Female & $19(\% 54.3)$ & $16(\% 45.7)$ & \multirow[b]{2}{*}{3.732} & \multirow[b]{2}{*}{0.053} \\
\hline & & Male & $14(\% 32.6)$ & $29(\% 67.4)$ & & \\
\hline & \multirow{2}{*}{ After Training } & Female & $16(\% 45.7)$ & $19(\% 54.3)$ & \multirow{2}{*}{2.659} & \multirow{2}{*}{0.103} \\
\hline & & Male & $12(\% 27.9)$ & $31(\% 72.1)$ & & \\
\hline \multirow[b]{2}{*}{ Buccal } & \multirow{2}{*}{ Before Training } & Female & $13(\% 37.1)$ & $22(\% 62.9)$ & \multirow{2}{*}{0.043} & \multirow{2}{*}{0.836} \\
\hline & & Male & $15(\% 34.9)$ & $28(\% 65.1)$ & & \\
\hline \multirow[t]{2}{*}{ Corridor } & \multirow{2}{*}{ After Training } & Female & $17(\% 48.6)$ & $18(\% 51.4)$ & \multirow{2}{*}{1.494} & \multirow{2}{*}{0.222} \\
\hline & & Male & $15(\% 34.9)$ & $28(\% 65.1)$ & & \\
\hline \multirow{4}{*}{ Midline Shift } & \multirow{2}{*}{ Before Training } & Female & $4(\% 11.4)$ & $31(\% 88.6)$ & \multirow{2}{*}{-} & \multirow{2}{*}{0.694} \\
\hline & & Male & $3(\% 7.0)$ & $40(\% 93.0)$ & & \\
\hline & \multirow{2}{*}{ After Training } & Female & $3(\% 9.3)$ & $32(\% 91.4)$ & \multirow{2}{*}{ - } & \multirow{2}{*}{1.000} \\
\hline & & Male & $4(\% 9.3)$ & $39(\% 90.7)$ & & \\
\hline \multirow[b]{2}{*}{ Incisal } & \multirow{2}{*}{ Before Training } & Female & $17(\% 48.6)$ & $18(\% 51.4)$ & \multirow{2}{*}{2.742} & \multirow{2}{*}{0.098} \\
\hline & & Male & $13(\% 30.2)$ & $30(\% 69.8)$ & & \\
\hline \multirow[t]{2}{*}{ Embrasure } & \multirow{2}{*}{ After Training } & Female & $13(\% 37.1)$ & $22(\% 62.9)$ & \multirow{2}{*}{0.179} & \\
\hline & & Male & $14(\% 32.6)$ & $29(\% 67.4)$ & & $0.0 / 2$ \\
\hline & & Female & $19(\% 54.3)$ & $16(\% 45.7)$ & & \\
\hline & Before Trainıng & Male & $24(\% 55.8)$ & $19(\% 44.2)$ & 0.018 & 0.893 \\
\hline Бाр Бानि & & Female & $8(\% 22.9)$ & $27(\% 77.1)$ & & \\
\hline & Aner Iranming & Male & $12(\% 27.9)$ & $31(\% 72.1)$ & 0.258 & 0.611 \\
\hline & D f & Female & $2(\% 5.7)$ & $33(\% 94.3)$ & & \\
\hline Midline & Detore Thaming & Male & $1(\% 2.3)$ & $42(\% 97.7)$ & - & - \\
\hline Diastema & & Female & $4(\% 11.4)$ & $31(\% 88.6)$ & & \\
\hline & Atter Iraining & Male & $1(\% 2.3)$ & $42(\% 97.7)$ & - & - \\
\hline & & Female & $0(\% 0.0)$ & $35(\% 100.0)$ & & \\
\hline & Detore Traming & Male & $0(\% 0.0)$ & $43(\% 100.0)$ & - & - \\
\hline & $A$ A Twi. & Female & $0(\% 0.0)$ & $35(\% 100.0)$ & & \\
\hline & К Н & Male & $0(\% 0.0)$ & $43(\% 100.0)$ & & \\
\hline & & Female & $30(\% 85.7)$ & $5(\% 14.3)$ & & \\
\hline & Betore Irainıng & Male & $23(\% 53.5)$ & $20(\% 46.5)$ & 9.201 & $0.002^{*}$ \\
\hline & & Female & $28(\% 80.0)$ & $7(\% 20.0)$ & & \\
\hline & After Iraining & Male & $23(\% 53.5)$ & $20(\% 46.5)$ & 5.992 & $0.014^{\wedge}$ \\
\hline
\end{tabular}

$(\mathrm{p}<0.05)$ 


\section{Discussion}

Society places a strong emphasis on physical appearance, and the smile is a key factor in facial attractiveness. An ideal smile is a feature that can have a significant impact on some aspects of a person's life. This can create professional and social disadvantages for people with unattractive smiles ${ }^{19}$. In the past few years, the number of patients requiring cosmetic dental procedures to obtain the perfect smile has greatly increased $^{8}$. To optimize smile esthetics, it is necessary for the modern clinician to appreciate the factors of a smile so that it can be improved ${ }^{8,19}$. This requires a comprehensive understanding of the complex relationship between the teeth, the gingival scaffold, and the lips ${ }^{8}$.

The architecture of gingival tissue has to be factored in when planning esthetic rehabilitation. The terms "red esthetics" and "pink esthetics" have been used to describe the ideal smiling gingival contour. An ideal smile arc has a slight contouring of the lower lip by the maxillary incisal edges $^{12}$. The smile arc can be classified as convex, curved, consonant, or deep plate-shaped, among others ${ }^{12,16}$. Yin et al. reported that young adults' smile esthetic perceptions were also significant and affected by gender and psychiatric personality traits ${ }^{20}$. In conformity with this study, there was a statistically significant relationship between gender and the answers given to the smile arc question before and after training $(\mathrm{p}<0.05)$. Female students had a 5.217-fold higher likelihood of choosing the ideal smile arc before training and a 3.478-fold higher likelihood of answering correctly after training.

The appearance of the gums and teeth during smiling, the skeletal shape, and the length and mobility of the upper lip affect the size and position of the anterior maxillary teeth. According to the literature, the smile line (lip line) is classified as low, medium, and high ${ }^{8}$. When there is a high lip line, a large part of the soft tissue that extends from the lower edge of the upper lip to the gingiva is apparent, which gives the appearance of what is called a gummy smile ${ }^{8}$. According to previous research, gum appearance alone is not the most critical esthetic factor; however, teeth and lips arranged according to this soft tissue may cause esthetic anxiety. The components of the smile that lie within the boundaries of the lip line should be arranged to be balanced and harmonious ${ }^{21}$.

Pausch et al. noted that when there is none or very little maxillary teeth apparent during smiling, which is typically seen in elderly persons, the appearance is the very unattractive ${ }^{22}$. Cracel-Nogueira et al. determined that the medium smile was the most admired smile, while the high smile was deemed the least esthetically appealing ${ }^{11}$. Sadrhaghighi et al. reported that education can affect the perception and assessment of smile components by observers ${ }^{17}$. In this study, the only question that had a statistically significant difference in responses before and after training was the smile or lip line question $(\mathrm{p}<$
0.05). Thirty-five students preferred the ideal gum view before training, while 58 participants did after training. Along with the training, students' awareness of gingival appearance increased.

Dark triangles play a key role in esthetic perception. Periodontitis, root angulation, improper dental treatment, and interproximal contact are the factors that cause dark triangles to form ${ }^{23}$. In this study, all dental students decided that dark triangles were not attractive.

A practical approach to positioning the midline of the facial references uses two anatomical landmarks. The first point is the nasion between the brows. The second is the philtrum base, which is also called "cupid's bow", in the upper lip center. A line drawn between these landmarks not only delineates the facial midline location but also defines the midline direction ${ }^{24}$. The midline between the maxillary central incisors should be coincidental with the midline of the nose whenever possible ${ }^{24,25}$. According to various studies, midline shift was the least noticeable component of an ideal smile ${ }^{11,12}$. However, in the current study, $91.0 \%$ of students did not find the midline shift attractive.

The midline diastema in the esthetic zone has been widely discussed in the literature. According to Machado, the diastemas are unesthetic, and all dental diastemas should be closed. Also, the size of the diastema and its proximity to the midline are inversely proportional to esthetic appeal ${ }^{12}$. Nogueira et al. reported that dental diastemas were considered unesthetic by both laypersons and clinicians, especially among young people ${ }^{11}$. Similarly, in this study, $96.2 \%$ of students did not find the midline diastema esthetically appealing.

Buccal corridors are defined as the area between the posterior teeth and the commissura when the patient is smiling ${ }^{12,26}$. According to Machado, the buccal corridor is not a significant factor in smile esthetics ${ }^{12}$. Moore et al. reported that there was no significant difference between perception of the buccal corridor and gender ${ }^{27}$. In this study, there was no statistically significant difference between the buccal corridor before and after training or with respect to gender.

Incisal embrasure is an important feature to improve esthetics and give a younger look to the smile ${ }^{12}$. Incisal embrasure areas are approximately in an inverse "V" shape, and as they move away from the midline, their size and volume increase ${ }^{8}$. Foulger et al. found that a lack of space for incisal embrasure has a negative effect on smile esthetics ${ }^{28}$. Parekh et al. reported that the majority of participants favored natural embrasures ${ }^{29}$. However, in this study, there was no statistically significant difference in responses to the incisal embrasure question before and after training, and there was no correlation between the incisal embrasure question and gender.

Several studies have reported guidelines regarding anterior esthetics in order to achieve excellent results. The "Golden Proportion" value is one of the most significant guidelines ${ }^{30}$. However, in the present study, there was 
no statistically significant difference in responses to the golden ratio question before and after training. The latter observation is consistent with the findings of Kokich et al. who found that symmetrical narrow lateral incisors may be acceptable in some situations ${ }^{13}$.

One of the main limitations of this study is that it only included second-grade dental students. Therefore, the participant population may need to be increased for future studies. Also, only eight smile esthetic components were studied, which may need to be increased in the future. Another limitation is that between ${ }^{16}$ images were presented to students at once in a single classroom. This could skew the responses of the students based on their location in the classroom. Based on the location of the screen, students at the front, sides, and rear may not have had similar vantage points.

\section{Conclusions}

Based on the limited results of this study, professional education may affect dental students' overall perception when evaluating smile esthetics. There was a difference in esthetic perception between males and females. Female dental students had better awareness of the smile arc component of smile esthetics. Successful esthetic results can be achieved by clinicians when they know and apply guidelines and pay attention to the components of smile esthetics. Therefore, dental students should learn these factors during their professional education.

\section{References}

1. Alhammadi MS, Halboub E, Al-Mashraqi AA, Al-Homoud M, Wafi S, Zakari A, et al. Perception of facial, dental, and smile esthetics by dental students. J Esthet Restor Dent, 2018;30:415-426.

2. Mousavi SM, Ghorani P, Deilamani A, Rakhshan V. Effects of laterality on esthetic preferences of orthodontists, maxillofacial surgeons, and laypeople regarding the lip position and facial convexity: a psychometric clinical trial. Oral Maxillofac Surg, 2019;23:439-451.

3. Sarver D, Ackerman M. Dynamic smile visualization and quantification: part 2. Smile analysis and treatment strategies. Am J Orthod Dentofacial Orthop, 2003;124:116127.

4. Nomura S, Freitas KMS, Silva PPC, Valarelli FP, Cancado RH, Freitas MR et al. Evaluation of the attractiveness of different gingival zeniths in smile esthetics. Dental Press J Orthod, 2018;23:47-57.

5. Al-Saleh SA, Al-Shammery DA., Al-Shehri NA, Al-Madi EM. Awareness of Dental Esthetic Standards Among Dental Students and Professionals. Clin Cosmet Investig Dent, 2019; 11:373-382.
6. Al Taki A, Hamdan AM, Mustafa Z, Hassan M, Abu-Alhuda S. Smile esthetics: Impact of variations in the vertical and horizontal dimensions of the maxillary lateral incisors. Eur $\mathrm{J}$ Dent, 2017;11:514-520.

7. Pinzan-Vercelino CRM, Costa ACS, Ferreira MC, Bramante FS, Fialho MPN, Gurgel JA. Comparison of gingival display in smile attractiveness among restorative dentists, orthodontists, prosthodontists, periodontists, and laypeople. J Prosthet Dent, 2020;123:314-321.

8. Sharma PK, Sharma P. Dental Smile Esthetics: The Assessment and Creation of the Ideal Smile. Semin Orthod, 2012;18:193-201.

9. Koidou VP, Chatzopoulos GS, Rosenstiel SF. Quantification of facial and smile esthetics. J Prosthet Dent, 2018;119:270277.

10. Koidou VP, Rosenstiel SF, Rashid RG. Celebrity smile esthetics assessment: smile angulation. J Prosthet Dent, 2016;117:636-641.

11. Cracel-Nogueira F, Pinho T. Assessment of the perception of smile esthetics by laypersons, dental students and dental practitioners. Int Orthod, 2013;11:432-444.

12. Machado AW. 10 commandments of smile esthetics. Dental Press J Orthod, 2014;19:136-157.

13. Kokich VO Jr, Kiyak HA, Shapiro PA. Comparing the perception of dentists and lay people to altered dental esthetics. J Esthet Dent, 1999;11:311-324.

14. Duarte MEA, Machado RM, Motta AFJ, Mucha JN, Motta AT. Morphological simulation of different incisal embrasures: perception of laypersons, orthodontic patients, general dentists and orthodontists. J Esthet Restor Dent, 2017;29:68-78.

15. Kim J, Topolski R, Dickinson D, Ramos Jr V. The influence of lip form on incisal display with lips in repose on the esthetic preferences of dentists and lay people. J Prosthet Dent, 2017;118:413-421.

16. Lombardi RE. The principles of visual perception and their clinical application to denture esthetics. J Prosthet Dent, 1973;29:358-382.

17. Sadrhaghighi H, Zarghami A, Sadrhaghighi S, Eskandarinezhad M. Esthetic perception of smile components by orthodontists, general dentists, dental students, artists, and laypersons. J Investig Clin Dent, 2017;8:27590143.

18. Springer NC, Chang C, Fields HW, Beck MF, Firestone $\mathrm{AR}$, Rosenstiel $\mathrm{S}$, et al. Smile esthetics from the laysperson's perspective. Am J Orthod Dentofacial Orthop, 2011;139:e91-101.

19. Dunn WJ, Murchison DF, Broome JC. Esthetics: patients' perceptions of dental attractiveness. J Prosthodont, 1996;5:166-171.

20. Yin L, Jiang M, Chen W, Smales RJ, Wang Q, Tang L. Differences in facial profile and dental esthetic perceptions between young adults and orthodontists. Am J Orthod Dentofac Orthop, 2014;145:750-756.

21. Garber DA, Salama MA. The aesthetic smile: diagnosis and treatment. Periodontol 2000, 1996;11:18-28.

22. Pausch NC, Katsoulis D. Gender-specific evaluation of variation of maxillary exposure when smiling. J Craniomaxillofac Surg, 2017;45:913-920.

23. Pugliese F, Hess R, Palomo L. Black triangles: Preventing their occurrence, managing them when prevention is not practical. Semin Orthod, 2019;25:175-186. 
24. Morley J, Eubank J. Macroesthetic elements of smile design. J Am Dent Assoc, 2001;132:39-45.

25. Silva BP, Jiménez-Castellanos E, Stanley K, Mahn E, Coachman C, Finkel S. Layperson's perception of axial midline angulation in asymmetric faces. J Esthet Restor Dent, 2018;30:119-125.

26. Rufenacht CR, Berger RP. Fundamentals of esthetics. Quintessence Publishing: Books, 1990.

27. Moore T, Southard KA, Casko JS, Qian F, Southard TE. Buccal corridors and smile esthetics. Am J Orthod Dentofacial Orthop, 2005;127:208-213.

28. Foulger T, Tredwin C, Gill D, Moles D. The influence of varying maxillary incisal edge embrasure space and interproximal contact area dimensions on perceived smile aesthetics. Br Dent J, 2010;209:E4.

29. Parekh SM, Fields HW Beck M, Rosenstiel S. Attractiveness of variations in the smile arc and buccal corridor space as judged by orthodontists and laymen. Angle Orthod, 2006;76:557-563.

30. Lakshmi S, Abraham A, Selvakumaran G, Sekar V, Annapoorni $\mathrm{H}$. Influence of aesthetic dental and facial measurements on patient satisfaction between genders in Indian patients. Tanta Dent J, 2015;12:197-202.
Conflict of Interests: Nothing to declare.

Financial Disclosure Statement: Nothing to declare.

Human Rights Statement: All the procedures on humans were conducted in accordance with the Helsinki Declaration of 1975, as revised 2000. Consent was obtained from the patient/s and approved for the current study by national ethical committee.

Animal Rights Statement: None required.

Received on September 13, 2020.

Revised on November 2, 2020.

Accepted on January 20, 2020.

Correspondence:

Gamze Paken

Department of Prosthodontics

College of Dentistry,

Usak University, Usak, Turkey

e-mail: gamze.paken@usak.edu.tr 